\title{
Surgical correction of trachomatous cicatricial entropion
}

\author{
J. H. SANDFORD-SMITH* \\ From the Christian Hospital, Quetta, Pakistan
}

The correction of trachomatous entropion and trichiasis has been practised since antiquity, and the ophthalmic literature from its earliest days has described methods for dealing with the condition. (A helpful review of the more established surgical procedures has been given by Fox (1970).)

The simplest operation is not always the best, but in areas of hyperendemic trachoma there is great pressure on limited medical resources and it may be necessary to delegate routine entropion surgery to paramedical assistants. Also the normal anatomical planes may be hard to identify in a very scarred and contracted lid; therefore, simplicity of technique is important.

The numerous procedures for the correction of cicatricial entropion are usually based on one of three original methods:

I. A skin approach with wedge resection of the tarsal plate but preserving the conjunctiva (Streatfield, 1859).

2. A conjunctival approach with preservation of the skin (Ewing, 1903; Lagleyze, 1905).

3. The insertion of a graft in the lid margin (Van Millingen, I887).

It was not until I955 that Wies suggested the possibility of a 'through-and-through' lid incision involving both skin and conjunctiva (Wies, 1955), a technique that had been used since antiquity but later neglected. The operation Wies described was for 'spastic' entropion of the lower lid, but it has also been recommended, sometimes with modifications, for cicatricial entropion of either lid (Ballen, 1964; King and Wadsworth, 1970; Beyer and Carroll, 1973).

Wies's technique has several advantages in the correction of trachomatous entropion. It is easy to perform and to teach, and no tissue is excised or grafted. The anterior approach is more convenient in lid surgery and as the tarsal plate and conjunctiva (the deforming structures) are incised the deformity is corrected and the lid margin free to rotate to any required position. The operation here described is basically that of Wies with some modifications to make it more suitable for cicatricial entropion of the upper lid.

Present address and requests for reprints: The Guinness Eye Clinic, Kaduna, Nigeria

\section{Operative technique}

After infiltration with local anaesthetic and adrenaline and topical anaesthetic drops to the conjunctiva, a spatulate lid guard is positioned to protect the eye and stretch the upper lid taut. (If only the central segment of the lid margin is affected a lid clamp may be used to ensure a bloodless field but it may prevent access to the medial and lateral margins of the lid.) The skin incision is made $4 \mathrm{~mm}$ from the lid margin and deepened through the orbicularis muscle to the tarsal plate. With blunt dissection the marginal orbicularis fibres and roots of the eyelashes are separated from the anterior surface of the tarsal plate so that this can be incised much nearer the lid margin and, if possible, slightly obliquely. The tarsal plate should be entered on its anterior surface as near to the lid margin as possible without in any way damaging the lash roots (in practice about $2.5 \mathrm{~mm}$ from the lid margin), and the conjunctiva pierced about 1.5 $\mathrm{mm}$ from the lid margin (Fig. $\mathrm{I}$ ).

This is the main difference from the technique of Wies. Incising the tarsal plate nearer the lid margin produces a better eversion of the marginal fragment bearing the lashes and also less deformity or shortening of the upper lid. Keeping the skin-muscle incision far from the lid margin safeguards the lash roots and the marginal blood supply. Three to four mattress sutures are then placed through the skin of the marginal fragment just above the lash line, into the substance of the tarsal plate about $2 \mathrm{~mm}$ above its cut edge, and back through the skin of the marginal fragment (Fig. 2).

The sutures are tied with only moderate tension and thus not requiring any rubber pegs or other method of fixation. The eversion is ensured because the conjunctiva and tarsal plate have been incised and the lid margin is therefore able to rotate freely. Should increased eversion be required the sutures need not be tied any tighter but the mattress suture should be placed higher up in the tarsal plate, thus increasing the angle of rotation. A reverse adjustment of the mattress suture will decrease the amount of eversion. This is a useful way of straightening the irregular trichiasis, which often occurs in trachoma, because some parts of the lid may require more correction than others. A considerable immediate postoperative over-correction is best aimed for because subsequent scar contracture will cause some inversion of the lid margin. Interrupted edge-to-edge skin sutures are then placed between the mattress sutures to close the wound.

After the operation the eye is padded for one day and antibiotic ointment applied daily. The skin wound usually heals in about six days, when the skin sutures may be removed, and the tarsoconjunctival wound in 


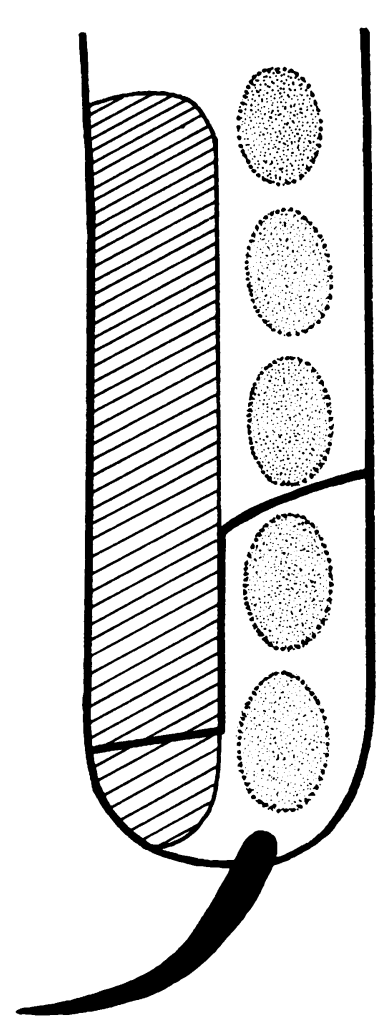

FIG. I Longitudinal section of eyelid showing plane of incision about 12 days, when the mattress sutures may be removed. All the sutures may be removed at the later date in patients who live far away and have difficulty in making a return visit, or absorbable sutures may be used in such cases.

\section{Results and discussion}

The operation described has now been carried out several hundred times in various situations where trachoma is endemic - in a rural eye 'camp' and in a district hospital in Pakistan, and a university hospital in Nigeria. Because any systematic followup of the patients was impossible a report of the results is bound to be only in the form of a clinical impression.

\section{COMPLICATIONS}

Under-correction or recurrence seemed to result from several factors. First, if the conjunctival incision was not complete a small tag of uncut conjunctiva might remain and prevent easy rotation of the lid margin. Secondly, it was important to make sure that the incision extended along the whole length of the affected part of the lid or else only the central portion would be adequately corrected. Thirdly, as already noted, postoperative wound contracture meant that an immediate over-correction was desirable. With experience and an awareness of these factors the incidence of under-correction and recurrence became negligible?

Because of the severe distichiasis associated with trachoma the position of many of the lashes had? often to be over-corrected in order to straighten the most inverted. So long as the over-correctiones involved only the lashes and lid margin and not the substance of the lid the final appearance was cosmetically acceptable. By placing the tarso $\vec{\omega}$ conjunctival incision as near as possible to the lide margin unsightly buckling and eversion of theo. substance of the lid was much less noticeable.

Granuloma formation occurred occasionally froms the conjunctival wound but was easily excised withif scissors without subsequent problems.

Bleeding at operation was often quite brisk from the marginal lid artery, which could be either ligated or included in one of the mattress sutures. In three cases there was quite a brisk. secondary haemorrhage which was stopped bye applying a firm pad and bandage.

No ischaemia of the lid margin or significant wound infection were observed, although mose patients had considerable chronic conjunctivitis? Cicatricial entropion of the lower lid was lessy common than in the upper and usually less severe However, it should be noted that over-correction is

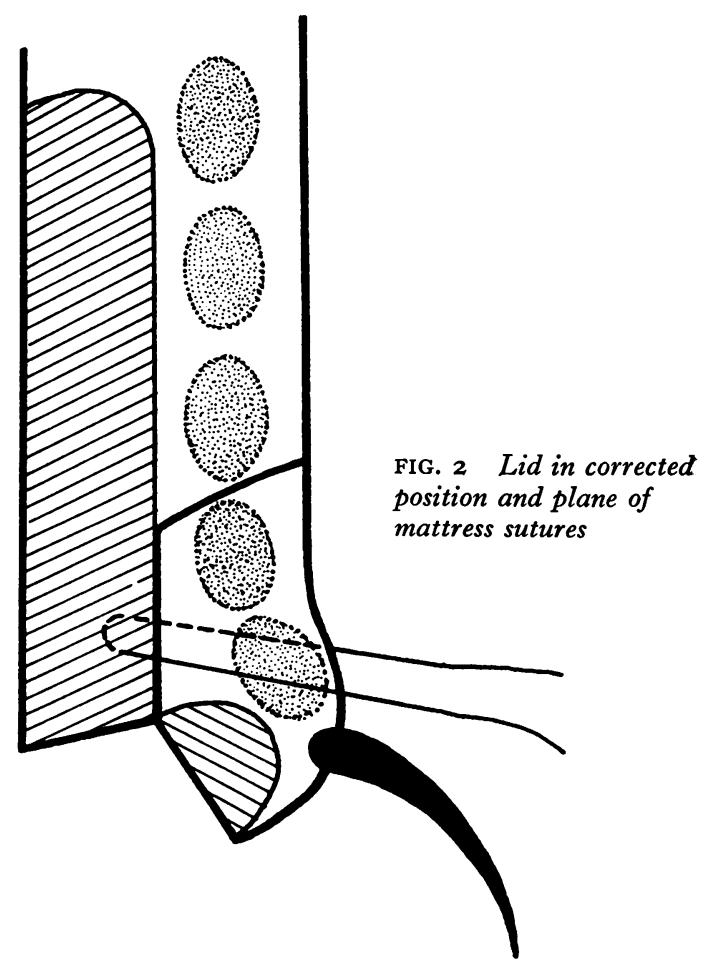

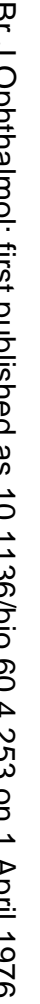


more easily produced in the lower lid, presumably because it is less rigid.

\section{Summary}

A modified version of Wies's operation for the correction of cicatricial entropion is described, the most important modification being a different plane for the incision through the eyelid. The possible complications and their prevention are discussed.

\section{References}

BALLEN, P. H. (1964) Arch. Ophthal., 72, 239

BEYER, C. K., and CARROLL, J. M. (1973) Ibid., 89, 33

EWING, A. E. (1903) Amer. F. Ophthal., 20, 33

Fox, S. A. (1970) 'Ophthalmic Plastic Surgery', 4th ed, p. 298. Grune \& Stratton, New York

KING, J. H., and WADSWORTH, J. A. c. (I970) 'An Atlas of Ophthalmic Surgery', p. 64. Lippincott \& Co,

Philadelphia

LAGLEYZE (1905) Ann. Ophthal., 14, 473

STREATFIELD, J. F. (1859) Roy. Lond. ophthal. Hosp. Rep., I, I 2 I

VAN MILLINGEN, E. (1887) Ophthal. Rev., 6, 309

wiEs, F. A. (1955) Trans. Amer. Acad. Ophthal. Otolaryng., 59, 503 